\title{
3D scapular orientation on healthy and pathologic subjects using stereoradiographs during arm elevation
}

\author{
Xavier Ohl, MD, PhD ${ }^{a, b}, *$, Nicola Hagemeister, PhD ${ }^{c}$, Cheng Zhang, PhD Student ${ }^{a, c}$, \\ Fabien Billuart, PhD $^{a}$, Olivier Gagey, MD, PhD ${ }^{d}$, Nathalie J. Bureau, MD, FRCPC, MSc ${ }^{c}$, \\ Wafa Skalli, PhD
}

\author{
${ }^{a}$ Institut de Biomécanique Humaine Georges Charpak, Paris, France \\ ${ }^{b}$ CHU Maison-Blanche, Service d'Orthopédie-Traumatologie, Reims, France \\ ${ }^{c}$ Laboratoire de recherche en Imagerie et Orthopédie, École de technologie supérieure, Centre de recherche du Centre \\ hospitalier de l'Université de Montréal, Montréal, Canada \\ ${ }^{d}$ Service de Chirurgie Orthopédique, CHU de Bicêtre, Université Paris 11, Le Kremlin-Bicêtre, France
}

Background: Alterations of the scapular kinematics in different pathologic conditions have been widely studied. However, results have shown considerable discrepancies concerning the direction and the amplitude of scapular movement. The lack of consistency in the literature probably has several explanations. The purpose of this study was to analyze scapular orientation with the arm at rest and with $90^{\circ}$ lateral elevation in healthy and pathologic subjects by use of stereoradiographs.

Materials and methods: All participants $(n=65)$ underwent a clinical examination and magnetic resonance imaging of the shoulder to assess rotator cuff status. Participants were separated into 3 groups: healthy, rotator cuff tear (RCT), and RCT and subacromial impingement syndrome (RCT+ SIS). A 3-dimensional model of the scapula was fitted to each low-dose stereoradiograph acquired with the arm at rest and $90^{\circ}$ arm elevation.

Results: Orientation of the scapula with the arm at rest was not significantly different between groups. During lateral elevation, scapular orientation was not significantly different between the healthy group and the RCT group. However, upward rotation was significantly reduced in the RCT + SIS group.

Conclusion: Alterations of scapular kinematics in symptomatic subjects are multifactorial. We observed a link between clinically assessed subacromial impingement and scapular orientation during lateral elevation of the arm.

Level of evidence: Basic Science, Kinesiology.

Keywords: Subacromial impingement syndrome; rotator cuff tear; scapula; stereoradiography; shoulder kinematics 
Table I Demographic data for healthy and pathologic subjects

\begin{tabular}{|c|c|c|c|c|}
\hline & Healthy group $(n=25)$ & RCT group $(n=17)$ & RCT + SIS group $(n=23)$ & $P$ value \\
\hline Gender & 11 women, 14 men & 10 women, 7 men & 9 women, 14 men & .322 \\
\hline Age (years) $( \pm 1 S D)$ & $55.3( \pm 7.8)$ & $53.3( \pm 7.9)$ & $57.8( \pm 7.0)$ & .187 \\
\hline $\begin{array}{l}\text { Constant score }(/ 100) \\
\text { mean }( \pm 1 \text { SD })\end{array}$ & $85.5( \pm 5.5)$ & $56.1( \pm 11.8)$ & $49.0( \pm 13.2)$ & $\begin{array}{l}<.001 \\
<.001^{\dagger} \\
.017^{\ddagger}\end{array}$ \\
\hline VAS for pain $(/ 10)$ & 0 & $5.5( \pm 2)$ & $6.1( \pm 2)$ & $\begin{array}{l}<.001^{*} \\
<.001^{\dagger} \\
.447^{\ddagger}\end{array}$ \\
\hline BMI $\left(\mathrm{kg} / \mathrm{m}^{2}\right)( \pm 1 \mathrm{SD})$ & $23.1( \pm 3.1)$ & $26.8( \pm 4.5)$ & $29.2( \pm 3.6)$ & $\begin{array}{l}.007^{*} \\
<.001^{\dagger} \\
.085^{\ddagger}\end{array}$ \\
\hline$<25$ & $21(84 \%)$ & $5(30 \%)$ & $4(17 \%)$ & \\
\hline$>25$ and $<30$ & $2(8 \%)$ & $6(35 \%)$ & $11(48 \%)$ & \\
\hline$>30$ & $2(8 \%)$ & $6(35 \%)$ & $8(35 \%)$ & \\
\hline
\end{tabular}

$R C T$, rotator cuff tear; SIS, subacromial impingement syndrome; SD, standard deviation; VAS, visual analog scale; BMI, body mass index.

* For $P$ value healthy group vs. RCT group.

$\dagger$ For $P$ value healthy group vs. RCT + SIS group.

$\ddagger$ For $P$ value RCT group vs. RCT + SIS group.

The clinical expression of rotator cuff tear (RCT) in the general population varies from asymptomatic to pseudoparalytic shoulders. ${ }^{21}$ There are different ways to explain this clinical observation, and scapular orientation analysis during elevation of the arm is one of them.

Numerous kinematic studies have analyzed scapular movement during arm elevation. ${ }^{16,26,29}$ In healthy subjects, the predominant movements are upward rotation and posterior tilt of the scapula in relation to the thorax coordinate system. ${ }^{1,2,15}$ In pathologic subjects, results show wide discrepancies concerning the direction and the amplitude of the scapular movement, 6,11,14,16-18,20,28 and no clear consensus can be drawn from the literature. For example, in a recent review of studies specifically investigating scapular orientation in pathologic subjects, Ludewig and Reynolds noticed that a significant decrease of the scapular upward rotation was observed in 4 of 9 studies, whereas 1 study showed increased upward rotation and 4 showed no significant difference. ${ }^{16}$ Because of this lack of consistency in the literature, we are not able to propose a pattern of impaired movement in relation to the pathologic status. Alterations in scapular orientation may be due to pain and impingement $^{7,10,14,18,30}$ or to RCT. ${ }^{22,25,27,28,32}$ In addition, there are many methodologic issues that could explain differences in comparing studies. ${ }^{16,26,29}$ To our knowledge, no studies have assessed the relationship between scapular position, RCT, and impingement in a cohort of healthy and pathologic subjects.

Our hypothesis was that clinical impairment of the shoulder can be explained by scapular orientation alterations with the arm at rest and $90^{\circ}$ arm abduction.

The aim of this study was first to compare the scapular orientation with the arm at rest in 3 groups of subjects: healthy, RCT and clinical impingement, and RCT without impingement. The second aim was to assess the scapular position with the arm at $90^{\circ}$ elevation in those 3 groups of subjects.

\section{Material and methods}

\section{Subjects}

This was a prospective, multicenter observational study; 25 healthy subjects and 40 pathologic subjects were included. A clinical examination was performed by a shoulder surgeon and included range of movement, impingement and rotator cuff examination, calculation of the Constant score, ${ }^{3}$ visual analog scale score for pain, and body mass index (BMI). All participants underwent magnetic resonance imaging (MRI) to assess rotator cuff status.

The inclusion criteria for the symptomatic group were (1) current chronic shoulder pain during active movement (all pathologic patients were recruited from a waiting list for rotator cuff repair) and (2) a full-thickness RCT involving at least 2 tendons (subscapularis and supraspinatus for 4 subjects, supraspinatus and infraspinatus for 33 subjects, and the 3 tendons for 3 subjects) assessed by an experienced radiologist on MRI. The existence of a subacromial impingement syndrome (SIS) was defined only from the clinical examination as a positive Hawkins and Neer test result $(\mathrm{RCT}+\mathrm{SIS}$ group, $\mathrm{n}=23)$. The other pathologic subjects were classified in the RCT group $(n=17)$. Demographic data are summarized in Table I. Most of the pathologic subjects did not achieve active full elevation, and we decided to analyze only posture at $90^{\circ}$ elevation for all groups.

Scapular orientation was calculated from stereoradiographic analysis with the arm at rest for the entire cohort and at $90^{\circ}$ elevation for selected subjects (subjects with orientation of the humeral shaft between $0^{\circ}$ and $30^{\circ}$ from the coronal plane [movement of abduction] in relation to the thorax coordinate system). This limitation was included a posteriori to avoid 
modifications of the scapular rotations resulting from the plane of arm elevation.

\section{Stereoradiograph acquisition}

This study used stereoradiographs acquired with the EOS system (EOS Imaging, Paris, France), which enables acquisition of 2 calibrated, low-dose, orthogonal radiographs with the subject standing at an angle of $30^{\circ}$ to $40^{\circ}$ coronal rotation to the plane of one of the x-ray beams to obtain true anterior-posterior and lateral views of the scapula and to limit superimposition with the rib cage and spine. ${ }^{24}$ Two arm positions (arm at rest and approximately $90^{\circ}$ elevation) were maintained by the subjects for 10 seconds during acquisition of the radiographs. Between positions, the subjects returned to resting position. No arm holder was used.

\section{D model reconstruction of the scapula}

For each subject, a personalized 3-dimensional (3D) reconstruction of the scapula was created following the method described by Lagacé et al. ${ }^{12}$ Briefly, the observer digitizes clearly visible anatomic landmarks on the stereoradiographs for each arm position. This step enables a first adjustment of a parameterized 3D model of the scapula, and from then on the observer can rigidly register on each stereoradiograph. By adding further information to these images (contours, non-stereo-correspondent landmarks), the prepersonalized model is iteratively adjusted until its retroprojection best fits the contours that are visible on the radiographs. This produces a 3D model of the scapula for each subject. In this model, the glenoid is parameterized by an ellipse. This ellipse is then used to construct the glenoid-centered coordinate system.

\section{Coordinate system construction}

The thorax coordinate system was constructed in accordance with International Society of Biomechanics recommendations ${ }^{31}$ (Fig. 1) based on the identification of radiopaque markers (6-mm-diameter tantalum beads) glued to the skin so as to palpate recommended landmarks before acquisition of the radiograph. For the scapula, we used a glenoid-centered coordinate system based on the ellipse fitted to the glenoid rim. The origin of this coordinate system was the ellipse center. ${ }^{23}$ The $Z$ axis was the perpendicular to the least squares plane fitted to the glenoid cavity. The $Y_{\mathrm{s}}$ axis was the vector between the lower and upper edges of the glenoid, projected onto the glenoid plane and oriented upward. The $\mathrm{X}_{\mathrm{s}}$ axis was the perpendicular common to $\mathrm{Y}_{\mathrm{s}}$ and $\mathrm{Z}_{\mathrm{s}}$, oriented forward (Fig. 2).

Each scapular coordinate system was described in the thorax coordinate system for each position $\left(0^{\circ}\right.$ and $90^{\circ}$ of arm elevation $)$. For each case, scapular orientation in the thorax coordinate system was calculated following a Y-X-Z angle sequence, as recommended. ${ }^{31}$ Movement of the scapula relative to the thorax coordinate system was defined as internal/external rotation (along the $\mathrm{Y}$ axis, positive was defined as internal rotation), upward/downward rotation (along the $\mathrm{X}$ axis, negative was defined as upward rotation), and anterior/posterior tilt (along the $\mathrm{Z}$ axis, positive was defined as posterior tilt). In a previous study, we showed that the most reproducible rotation was upward/downward rotation (x axis) using this technique. ${ }^{23}$

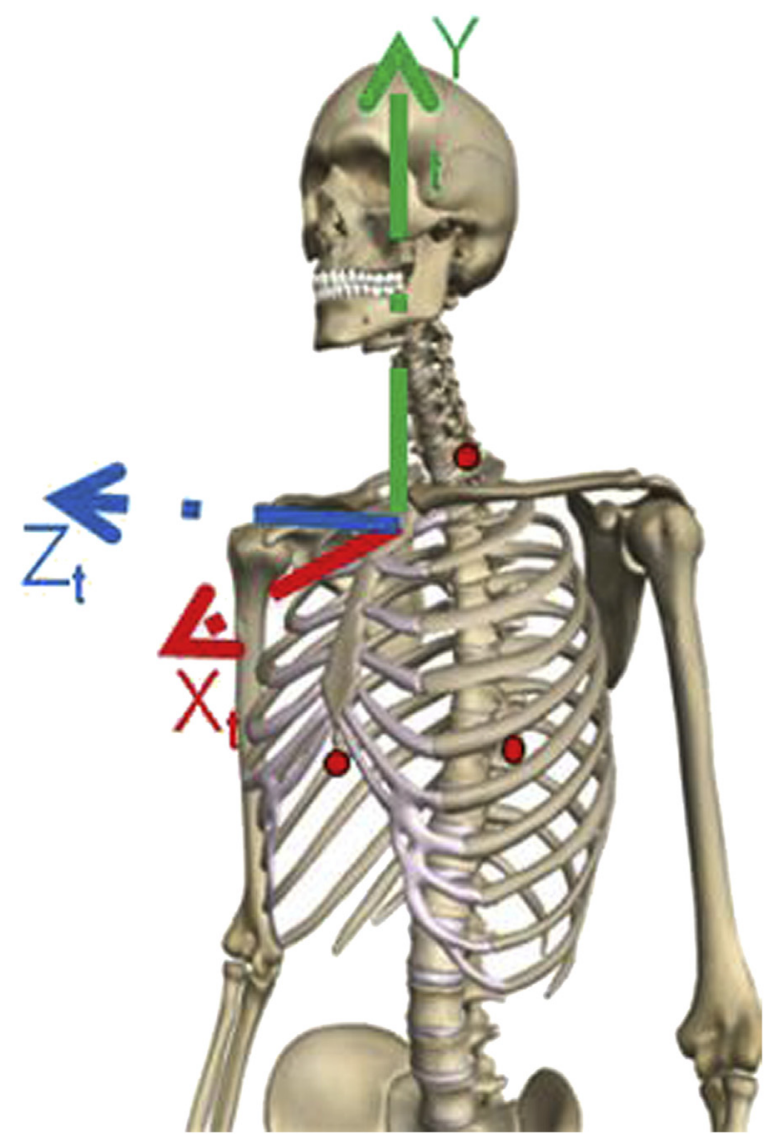

Figure 1 Representation of the thorax coordinate system as recommended by the International Society of Biomechanics. The center of this coordinate system is the incisura jugularis.

\section{Statistical analysis}

Statistical analysis was performed with commercial software (SPSS Inc., Chicago, IL, USA), and the level of significance was set at $P<.05$. Univariate analysis of variance was used to compare the 3 groups. Dependent variables were the Constant score, BMI, the visual analog scale score for pain, and the measures of scapular orientation (along 3 axes). The Bonferroni test was used as a post hoc test to determine differences between groups. An analysis of covariance was used to determine whether BMI was a confounding variable for scapular orientation with the arm at rest.

\section{Results}

Our statistical analysis found a significant difference for BMI and for the Constant score between groups (Table I). The orientation of the scapula in relation to the thorax coordinate system with the arm at rest is summarized in Table II, and no significant differences appeared between groups. BMI did not appear as a significant covariable for the orientation of the scapula with the arm at rest.

Scapular orientation at $90^{\circ}$ arm elevation was assessed for subjects with an adequate set of biplanar stereoradiographs 

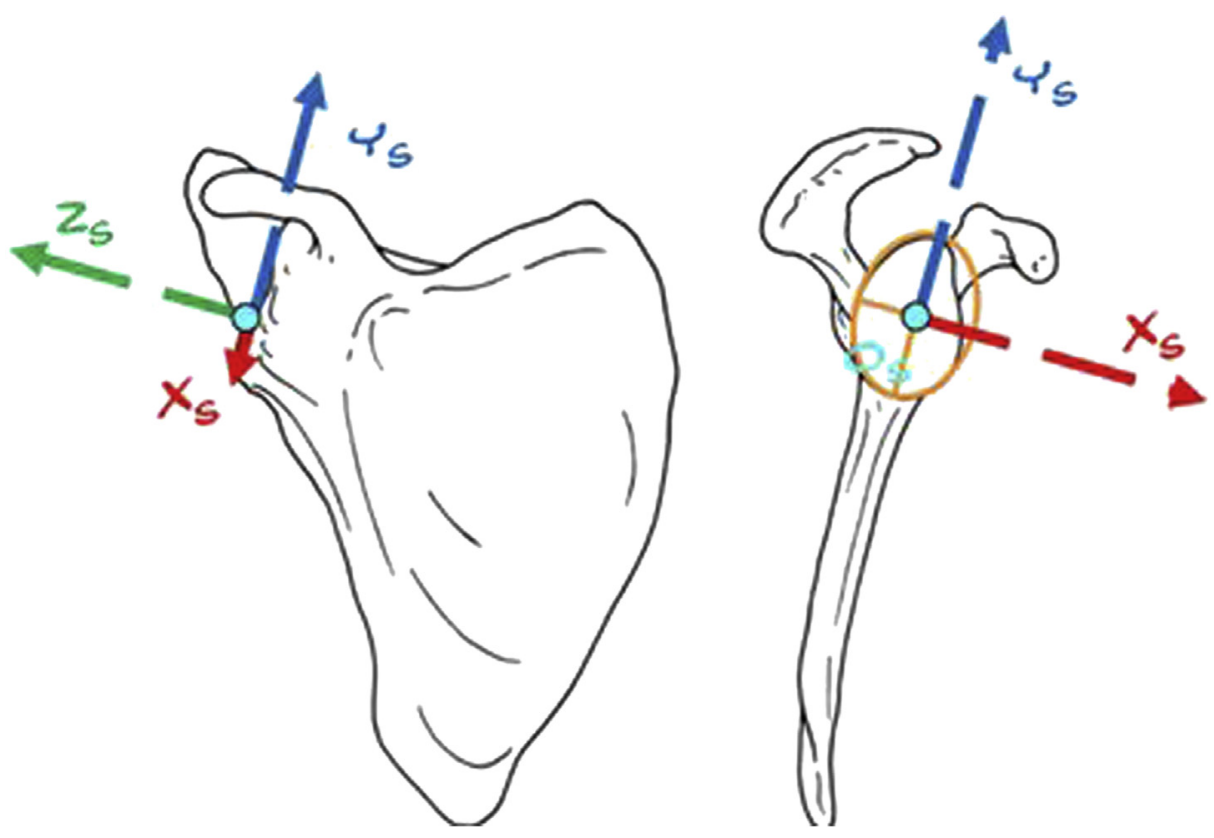

Figure 2 Representation of the scapular coordinate system used in this study. This coordinate system is glenoid centered.

Table II Scapular orientation with arm at rest for all groups $(n=65)$

\begin{tabular}{|c|c|c|c|c|}
\hline & Healthy subjects $(n=25)$ & RCT group $(n=17)$ & $\mathrm{RCT}+$ SIS group $(\mathrm{n}=23)$ & $P$ value \\
\hline Along $Y$ axis, mean $( \pm 1$ SD $)$ & $42.6^{\circ}\left( \pm 6.2^{\circ}\right)$ & $43.3^{\circ}\left( \pm 6.4^{\circ}\right)$ & $46.3^{\circ}\left( \pm 7.0^{\circ}\right)$ & .137 \\
\hline Along $X$ axis, mean $( \pm 1$ SD $)$ & $6.0^{\circ}\left( \pm 6.4^{\circ}\right)$ & $4.7^{\circ}\left( \pm 4.0^{\circ}\right)$ & $2.1^{\circ}\left( \pm 6.3^{\circ}\right)$ & .082 \\
\hline Along $Z$ axis, mean $( \pm 1$ SD) & $-27.3^{\circ}\left( \pm 6.6^{\circ}\right)$ & $-30.3^{\circ}\left( \pm 6.0^{\circ}\right)$ & $-30.7^{\circ}\left( \pm 8.7^{\circ}\right)$ & .063 \\
\hline
\end{tabular}

$R C T$, rotator cuff tear; SIS, subacromial impingement syndrome; $S D$, standard deviation.

corresponding to an abduction of the arm (a posteriori analysis of the humeral shaft orientation in relation to the thorax). The angle between the humeral shaft and the vertical axis (EOS reference frame) was between $78^{\circ}$ and $95^{\circ}$ (mean, $83^{\circ}$ ). Thirty-four patients were included for the kinematic analysis (healthy group, $\mathrm{n}=12 ; \mathrm{RCT}$ group, $\mathrm{n}=7 ; \mathrm{RCT}+\mathrm{SIS}$ group, $\mathrm{n}=15)$. The results are summarized in Table III. Upward rotation at $90^{\circ}$ arm elevation was significantly different between healthy subjects and the RCT + SIS group $(P<.045)$ (Fig. 3).

\section{Discussion}

Scapular orientation in relation to the thorax was similar with the arm at rest between healthy and pathologic subjects. During arm elevation at $90^{\circ}$ abduction, we observed that the upward rotation was significantly reduced in the RCT + SIS group compared with the healthy group. Other parameters of the movement were not significantly modified.

Analysis of the initial position of the scapula (arm at rest) enables an exploration of modifications of scapular orientation between groups. Indeed, an abnormal position of the scapula could result in a reduced subacromial space during arm elevation. In this study, as in the literature, ${ }^{11,14,17}$ we did not find any difference of scapular orientation with the arm at rest between groups. BMI was significantly different between groups but was not found to be a confounding factor influencing scapular orientation with the arm at rest. Likewise, this study did not show that the initial orientation of the scapula was responsible for the clinical differences observed.

Alterations of scapular kinematics in subjects with degenerative changes of the rotator cuff are multifactorial. On the one hand, there are modifications caused by pain and subacromial impingement ${ }^{4,7,11,13,14,17,18,30}$; one the other, there are alterations due to the RCT itself. $7,16,19,20,32$ Our study shows that the existence of a clinical impingement can affect the scapular orientation in different groups of subjects during arm elevation.

Many studies have reported results concerning subacromial impingement. The results of these studies are controversial because the kinematic measures found vary widely. $^{4,13,14,17,18}$ Like other authors, ${ }^{4,13,14}$ we noted a 
Table III Scapular orientation for all groups at $90^{\circ}$ arm elevation

\begin{tabular}{|c|c|c|c|c|}
\hline & Healthy subjects $(n=12)$ & $\mathrm{RCT}$ group $(\mathrm{n}=7)$ & RCT + SIS group $(n=15)$ & $P$ value \\
\hline External rotation $\left({ }^{\circ}\right)$ along $Y$ axis & $4.2( \pm 10.1)$ & $2.3( \pm 9.2)$ & $0.7( \pm 9.9)$ & .664 \\
\hline Upward rotation $\left({ }^{\circ}\right)$ along $X$ axis & $36.1( \pm 7.6)$ & $34.9( \pm 7.9)$ & $30.1( \pm 7.1)$ & $\begin{array}{l}.782^{*} \\
.045^{\dagger} \\
.492^{\ddagger}\end{array}$ \\
\hline Posterior tilt $\left({ }^{\circ}\right)$ along $\mathrm{Z}$ axis & $9.0( \pm 4.3)$ & $8.4( \pm 6.0)$ & $6.0( \pm 6.4)$ & .368 \\
\hline
\end{tabular}

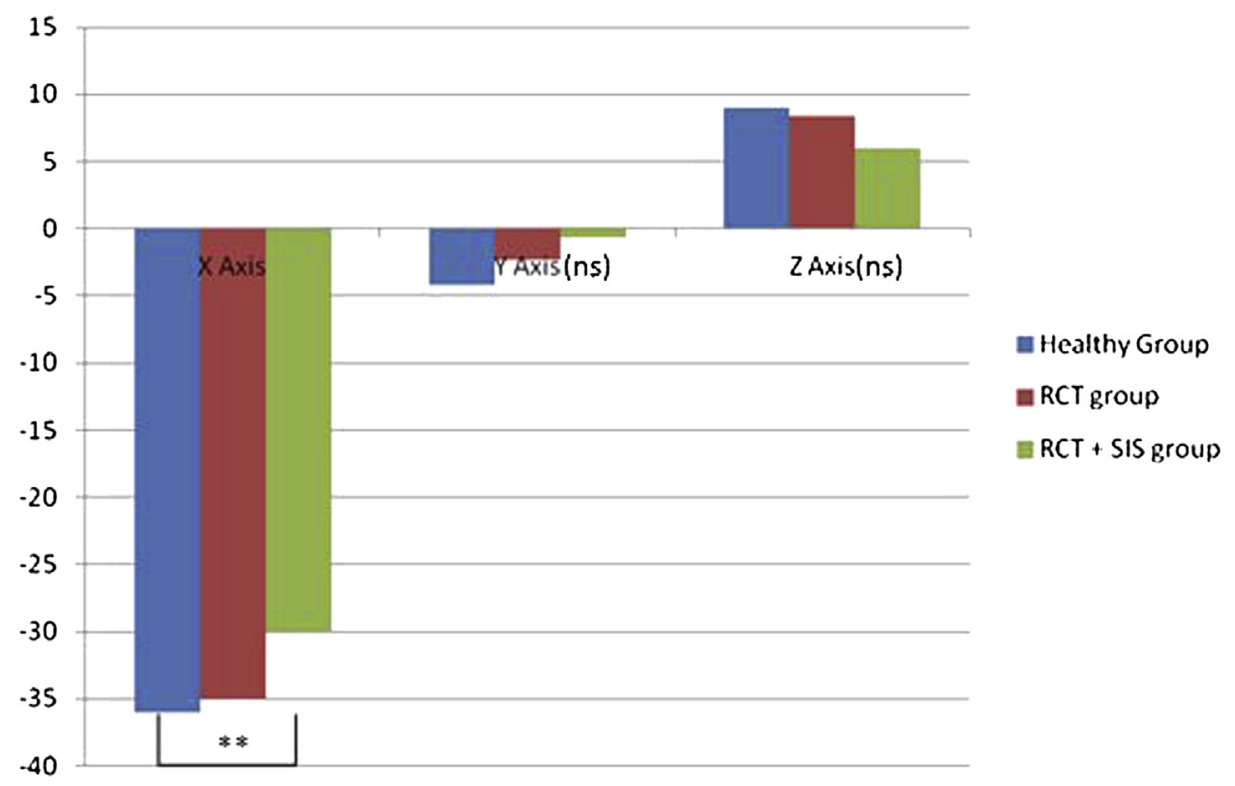

Figure 3 Representation of the scapular orientation at $90^{\circ}$ lateral elevation for the 3 groups (ns, not significant). **Significant difference between healthy and RCT + SIS group $(P<.05)$.

significant reduction in upward rotation during arm elevation in the RCT + SIS group compared with the healthy group. Alterations of scapular orientation could be the cause of the impingement by a reduction of the subacromial space, which could contribute to prolonging pain. In other studies, alterations of the scapular orientation appear as the consequences of subacromial pain. Wassinger et $\mathrm{al}^{30}$ reported an increase in upward rotation in case of induced subacromial pain in healthy subjects. In this study, the authors considered that in case of subacromial pain, the healthy shoulder can develop a compensatory mechanism to maintain a correct subacromial space. This hypothesis was verified by Scibek et $\mathrm{al}^{28}$ in 2008 on subjects with RCT after subacromial injection of lidocaine. Our results are in accordance with this. We showed that the scapular orientation in pathologic subjects with SIS was significantly altered, whereas subjects with RCT without impingement presented an orientation of the scapula that was similar to that of healthy subjects.
A lot of research has studied the effect of RCT on scapular kinematics. ${ }^{7,16,20,25,28,32}$ These studies showed a trend (nonsignificant) toward an increase of upward rotation. McCully et $\mathrm{al}^{19}$ also reported this trend in a study of healthy subjects before and after a suprascapular nerve block, which produces an experimental RCT. In our study, scapular orientation in the RCT group was not significantly different compared with the healthy subjects during arm elevation.

We then considered the possibility of compensatory mechanisms in case of subacromial impingement, pain, or RCT. These mechanisms tend to increase the subacromial space by way of an increasing upward rotation. This phenomenon enables correct function of the shoulder to be maintained in certain cases. When compensatory mechanisms are no longer effective, we observe a vicious circle in which a decrease of the scapular upward rotation causes a decrease in the subacromial space, causing pain and shoulder impairment. In our study, the subjects with RCT 
alone had a scapular orientation similar to that of healthy subjects and better function than subjects with RCT + SIS. In this last group, a specific program of rehabilitation of the periscapular muscles should enable correct function to be restored by increasing the upward rotation movement of the scapula.

In clinical practice, the analysis of the scapular orientation of both shoulders (healthy and pathologic) should determine whether compensatory mechanisms are insufficient.

This work presents some limitations. First, the comparative analysis of the 3 groups showed a significant difference regarding weight and BMI, and this may have an influence on scapular orientation. ${ }^{9}$ In further studies, we should ensure that the subject groups are comparable for BMI. Second, the groups for which $90^{\circ}$ arm elevation was available were small, and larger groups are needed. Third, we used the Hawkins and Neer tests to define the impingement syndrome. This choice is controversial. The impingement syndrome is itself controversial, and the reliability of the clinical tests seems to be poor. There are, however, some strengths in this work. First, we studied a reproducible posture of the arm with ascertainment of the plane of arm elevation. This method avoids the dispersal of the rotation along the $\mathrm{Y}$ axis. ${ }^{5,8}$ Second, the pathologic subjects presented similar RCTs concerning at least 2 tendons. Third, the MRI study of the healthy group enables the absence of asymptomatic tear to be ascertained. Fourth, the subject groups were comparable for mean age.

\section{Conclusion}

This study shows that scapular orientation with the arm at rest is similar between healthy and pathologic subjects. However, during lateral elevation, the analysis of scapular orientation evidences a reduction in upward rotation for the group with RCT and subacromial impingement compared with the healthy group. Adequate understanding of alterations in scapular kinematics is needed to restore shoulder function in symptomatic subjects.

\section{Acknowledgment}

We would like to thank P. Tetrault, D. Rouleau, and A. Roy for their technical and clinical support.

\section{Disclaimer}

The authors, their immediate families, and any research foundation with which they are affiliated have not received any financial payments or other benefits from any commercial entity related to the subject of this article.

\section{References}

1. Borstad JD, Ludewig PM. Comparison of scapular kinematics between elevation and lowering of the arm in the scapular plane. Clin Biomech (Bristol, Avon) 2002;17:650-9. http://dx.doi.org/10.1016/S02680033(02)00136-5

2. Bourne DA, Choo AM, Regan WD, MacIntyre DL, Oxland TR. Threedimensional rotation of the scapula during functional movements: an in vivo study in healthy volunteers. J Shoulder Elbow Surg 2007;16: 150-62. http://dx.doi.org/10.1016/j.jse.2006.06.011

3. Constant CR, Gerber C, Emery RJ, Sojbjerg JO, Gohlke F, Boileau P. A review of the Constant score: modifications and guidelines for its use. J Shoulder Elbow Surg 2008;17:355-61. http://dx.doi.org/10. 1016/j.jse.2007.06.022

4. Endo K, Ikata T, Katoh S, Takeda Y. Radiographic assessment of scapular rotational tilt in chronic shoulder impingement syndrome J Orthop Sci 2001;6:3-10.

5. Giphart JE, Brunkhorst JP, Horn NH, Shelburne KB, Torry MR, Millett PJ. Effect of plane of arm elevation on glenohumeral kinematics: a normative biplane fluoroscopy study. J Bone Joint Surg Am 2013;95:238-45. http://dx.doi.org/10.2106/JBJS.J.01875

6. Graichen H, Bonel H, Stammberger T, Haubner M, Rohrer H, Englmeier KH, et al. Three-dimensional analysis of the width of the subacromial space in healthy subjects and patients with impingement syndrome. AJR Am J Roentgenol 1999;172:1081-6.

7. Graichen H, Stammberger T, Bonel H, Wiedemann E, Englmeier KH, Reiser M, et al. Three-dimensional analysis of shoulder girdle and supraspinatus motion patterns in patients with impingement syndrome. J Orthop Res 2001;19:1192-8.

8. Grewal TJ, Dickerson CR. A novel three-dimensional shoulder rhythm definition that includes overhead and axially rotated humeral postures J Biomech 2013;46:608-11. http://dx.doi.org/10.1016/j.jbiomech. 2012.09.028

9. Gupta M, Dashottar A, Borstad JD. Scapula kinematics differ by body mass index. J Appl Biomech 2013;29:380-5.

10. Hébert LJ, Moffet H, Dufour M, Moisan C. Acromiohumeral distance in a seated position in persons with impingement syndrome. J Magn Reson Imaging 2003;18:72-9. http://dx.doi.org/10.1002/jmri.10327

11. Hébert LJ, Moffet H, McFadyen BJ, Dionne CE. Scapular behavior in shoulder impingement syndrome. Arch Phys Med Rehabil 2002;83: 60-9. http://dx.doi.org/10.1053/apmr.2002.27471

12. Lagacé PY, Cresson T, Hagemeister N, Billuart F, Ohl X, De Guise J, et al. 3D reconstruction of the scapula from biplanar radiographs. Proc SPIE 8314, Medical Imaging 2012: Image Processing, 83143L; February 23, 2012. doi:10.1117/12.911527.

13. Lin JJ, Hanten WP, Olson SL, Roddey TS, Soto-quijano DA, Lim HK, et al. Functional activity characteristics of individuals with shoulder dysfunctions. J Electromyogr Kinesiol 2005;15:576-86. http://dx.doi. org/10.1016/j.jelekin.2005.01.006

14. Ludewig PM, Cook TM. Alterations in shoulder kinematics and associated muscle activity in people with symptoms of shoulder impingement. Phys Ther 2000;80:276-91.

15. Ludewig PM, Phadke V, Braman JP, Hassett DR, Cieminski CJ, LaPrade RF. Motion of the shoulder complex during multiplanar humeral elevation. J Bone Joint Surg Am 2009;91:378-89. http://dx.doi. org/10.2106/JBJS.G.01483

16. Ludewig PM, Reynolds JF. The association of scapular kinematics and glenohumeral joint pathologies. J Orthop Sports Phys Ther 2009;39: 90-104. http://dx.doi.org/10.2519/jospt.2009.2808 
17. Lukasiewicz AC, McClure P, Michener L, Pratt N, Sennett B. Comparison of 3-dimensional scapular position and orientation between subjects with and without shoulder impingement. J Orthop Sports Phys Ther 1999;29:574-83. discussion 584-6.

18. McClure PW, Michener LA, Karduna AR. Shoulder function and 3-dimensional scapular kinematics in people with and without shoulder impingement syndrome. Phys Ther 2006;86:1075-90.

19. McCully SP, Suprak DN, Kosek P, Karduna AR. Suprascapular nerve block disrupts the normal pattern of scapular kinematics. Clin Biomech (Bristol, Avon) 2006;21:545-53. http://dx.doi.org/10.1016/j. clinbiomech.2006.02.001

20. Mell AG, LaScalza S, Guffey P, Ray J, Maciejewski M, Carpenter JE, et al. Effect of rotator cuff pathology on shoulder rhythm. J Shoulder Elbow Surg 2005;14:58S-64S. http://dx.doi.org/10.1016/j.jse.2004.09.018

21. Minagawa H, Yamamoto N, Abe H, Fukuda M, Seki N, Kikuchi K, et al. Prevalence of symptomatic and asymptomatic rotator cuff tears in the general population: from mass-screening in one village. J Orthop 2013;10:8-12. http://dx.doi.org/10.1016/j.jor.2013.01.008

22. Myers JB, Hwang JH, Pasquale MR, Blackburn JT, Lephart SM. Rotator cuff coactivation ratios in participants with subacromial impingement syndrome. J Sci Med Sport 2009; 12:603-8. http://dx.doi. org/10.1016/j.jsams.2008.06.003

23. Ohl X, Lagacé PY, Billuart F, Gagey O, Skalli W, Hagemeister N. Robustness and reproducibility of a glenoid-centered scapular coordinate system derived from low-dose stereoradiography analysis. J Appl Biomech 2015;31:56-61. http://dx.doi.org/10.1123/jab.20130310

24. Ohl X, Stanchina C, Billuart F, Skalli W. Shoulder bony landmarks location using the EOS low-dose stereoradiography system: a reproducibility study. Surg Radiol Anat 2010;32:153-8. http://dx.doi.org/10. 1007/s00276-009-0566-Z
25. Phadke V, Camargo P, Ludewig P. Scapular and rotator cuff muscle activity during arm elevation: a review of normal function and alterations with shoulder impingement. Rev Bras Fisioter 2009;13:1-9. http://dx.doi.org/10.1590/S1413-35552009005000012

26. Ratcliffe E, Pickering S, McLean S, Lewis J. Is there a relationship between subacromial impingement syndrome and scapular orientation? A systematic review. Br J Sports Med 2014;48:1251-6. http://dx. doi.org/10.1136/bjsports-2013-092389

27. Reddy AS, Mohr KJ, Pink MM, Jobe FW. Electromyographic analysis of the deltoid and rotator cuff muscles in persons with subacromial impingement. J Shoulder Elbow Surg 2000;9:519-23.

28. Scibek JS, Mell AG, Downie BK, Carpenter JE, Hughes RE. Shoulder kinematics in patients with full-thickness rotator cuff tears after a subacromial injection. J Shoulder Elbow Surg 2008;17:172-81. http:// dx.doi.org/10.1016/j.jse.2007.05.010

29. Struyf F, Nijs J, Baeyens JP, Mottram S, Meeusen R. Scapular positioning and movement in unimpaired shoulders, shoulder impingement syndrome, and glenohumeral instability. Scand J Med Sci Sports 2011; 21:352-8. http://dx.doi.org/10.1111/j.1600-0838.2010.01274.x

30. Wassinger CA, Sole G, Osborne H. Clinical measurement of scapular upward rotation in response to acute subacromial pain. J Orthop Sports Phys Ther 2013;43:199-203. http://dx.doi.org/10.2519/jospt.2013.4276

31. Wu G, van der Helm FC, Veeger HE, Makhsous M, Van Roy P, Anglin C, et al. ISB recommendation on definitions of joint coordinate systems of various joints for the reporting of human joint motion-Part II: shoulder, elbow, wrist and hand. J Biomech 2005;38:981-92. http:// dx.doi.org/10.1016/j.jbiomech.2004.05.042

32. Yamaguchi K, Sher JS, Andersen WK, Garretson R, Uribe JW, Hechtman $\mathrm{K}$, et al. Glenohumeral motion in patients with rotator cuff tears: a comparison of asymptomatic and symptomatic shoulders. J Shoulder Elbow Surg 2000;9:6-11. 